The selective account of the Council's work entitled "Some Aspects of Medical Research" is, like the similar section in the preceding report, a valuable discussion of modern knowledge of the following subjects : research on proteins, the preservation of spermatozoa and other cells at low temperatures, statistics in medical research, whooping cough, tuberculosis, antibiotics, diseases of the eye and skin, the experimental study of human skilled performance, climatological medicine, cortisone and adrenocorticotropic hormone, malaria, and insecticides. It is impossible, in the space available in this article, to do more than indicate in this way the scope of this interesting section. It does not cover, and it is not intended to cover, the full extent of the Council's activities and interests, the breadth of which is realized only by a study of the research programmes of the Council's numerous departments.

The reports of the Medical Research Council, and also those of kindred organizations, reveal the noble uses to which scientific work is actually being put. Not only is science daily saving the lives and mitigating the suffering of human beings and animals; it is also extending the span of life, fitting it to the demands of modern civilization and preparing for later generations a better and a healthier world. There is much in the history and literature of the world to remind one of man's desire to help his fellows and other living things ; but readers of the reports of the Medical Research Council may well ask themselves where else, outside unpretentious documents such as these, a man may find a comparable record of human labour entirely devoted to the welfare of mankind.

G. LAPAgE

\section{PHOTOGRAPHY IN RESEARCH AT THE UNIVERSITY}

$\mathrm{O}^{\mathrm{s}}$ $\mathrm{N}$ October 4 nearly two hundred people gathered at the Zoology School, Cambridge, to hear a series of short papers on the applications of photography to research in the university. This very successful all-day symposium was organized by the Scientific and Technical Group of the Royal Photographic Society and made possible largely through the enthusiastic co-operation of a number of Cambridge workers, including Prof. J. Gray, Dr. R. H. J. Brown, Mr. A. M. P. Brookes, Mr. Fairfax-Fozzard and Dr. J. S. Courtney-Pratt.

Mr. V. Gallafent opened the symposium by outlining the aims and objects of the Scientific and Technical Group in the advancement of photography. The Second World War, and its after-effects, have prevented the Group from acting on its agreed policy of fostering subsections in the provincial centres. The present meeting at Cambridge marked the first real step towards the realization of this policy ; and it was clear that it was a popular one.

A résumé of photographic reciprocity failure by Dr. W. F. Berg led to an interesting discussion on the merits of latensification by a long, low-intensity exposure after the short camera exposure. Mr. G. S. Moore urged, from the floor, that full development in a low-contrast metol developer would give as much speed as could be achieved by latensification, but possibly the latter process gives finer grain at a given $\gamma$ (which defines contrast in the image).

In a very clear paper, Mr. A. M. P. Brookes presented what might best be called a system of approach to any problem in high-speed photography as applied to engineering. It is usual to decide the exposuretime first. Still and ciné techniques differ inasmuch as the shutter-speed for a photograph destined to be examined as a still needs to be shorter than that for a ciné frame, where slight blurring helps to produce a jerk-free movement on projection. Mr. Brookes showed a graph from which the exposure-time could be read off against subject-speed after allowing for scaling-down in the camera. The graph was based on a $0 \cdot 1-\mathrm{mm}$. movement of image on the emulsion. For illumination of the subject, counting the light output from a photoflood as 1 , a studio light would be 10, a high-intensity mercury are 50, a flashbulb 1,000 , and a discharge tube 10,000 .

Dr. R. H. J. Brown, of the Department of Zoology, Cambridge, was principally interested in the study of animal movements - the flexure of a pigeon's wings, fish swimming, etc. $\mathrm{He}$ dealt, in his paper, mainly with the problems of illumination. For microcinematography the BTH type $F A 5$ lamp having a source $4.5 \mathrm{~mm}$. in length is very good. It can be run continuously at $125 \mathrm{~W}$. or flashed at a rate equivalent to $3 \frac{1}{2} \mathrm{~kW}$.

Mr. H. S. L. Harris described experimental difficulties in connexion with the bringing into operation of a mercury-vapour flash-tube for the photoelastic study of the stressing of gear teeth while running under load.

In the afternoon session Mr. R. G. Horner read a short paper on the limitations of colour photography in the recording of colour. Colour photography is sold to the public in order to give pleasing pictures, and it was never intended as a simple short-cut to colorimetry. When used for recording colours, it is necessary to apply all the standard photometric techniques used in photographic photometry.

A particularly interesting paper was presented by Prof. J. S. Mitchell (professor of radiotherapeutics in the University of Cambridge) dealing with ultraviolet and fluorescence photography, particularly that of cancerous tumours. Work is in progress on the relation between the disturbance of cellular nucleic acid metabolism (as revealed by ultra-violet absorption) and the production of structural changes in chromosomes by the therapeutic doses of irradiation.

Animal experiments have confirmed the increased fluorescence to ultra-violet light of the actively growing parts of the tumour and some other tissues following the injection of tracers. Prof. Mitchell appealed for guidance in colour-photographing the yellow fluorescence of the dissected tissues so as to yield quantitative results. A similar appeal was made by Dr. K. W. Rizk, who is engaged in recording the flow patterns that occur when water containing a blue indicator (such as litmus) is injected into a tank containing a colourless solution that turns the indicator red. Dr. Rizk was disappointed to find that the boundary between the blue central cone of the jet and the red mantle varied according to the camera exposure. No help was forthcoming from the meeting for Prof. Mitchell or Dr. Rizk beyond a re-emphasis of the limitations of commercial colourprocesses.

In the section on radiation microscopy, Dr. V. E. Cosslett (Cavendish Laboratory) considered the suitability of photographic materials for electron and X-ray work. For ordinary work the available materials are satisfactory, but for some purposes it would be advantageous to have specially improved materials. Dr. Cosslett appealed for more work to 
be carried out on the relationship between electron voltage and the characteristics of the photographic materials exposed to them. Very puzzling is the marked difference in response of photographic emulsions to electrons and $\mathrm{X}$-rays.

Dr. J. W. Menter (Physics and Chemistry of Surfaces Laboratory, Cambridge) showed some very fine electron-reflexion micrographs of solid surfaces. These were obtained using a Metrovick E.M.3 electron microscope that had been adapted for reflexion work.

Mr. W. D. Kemp dealt with the application of television to the recording of motion-picture films. There is no space here to follow the detailed technical argument, but it was summed up well in the short film that was projected.' The quality was far above anything seen on the broadcast television screen. Questioned as to whether the lines had been eliminated by spot-wobble, Mr. Kemp replied that they had been visible on the negative but were lost in the printing stage.

In the last paper of the symposium Mr. J. G. Yates described the experimental difficulties attending the slow-speed recording of low-frequency 'noises' such as the spontaneous variations in carbon resistors that occur under load.

\section{FULMER RESEARCH INSTITUTE OPEN DAY}

A $\mathrm{N}$ open day was held at the Fulmer Research A Institute on September 30 to mark the completion of the first five years of work at the Institute; it was also the occasion for unveiling a memorial plaque to the founder, the late Colonel W. C. Devereux. After welcoming the guests, Mr. Percy Horsfall, chairman of the group of companies forming Almin, Ltd., explained that the Institute has been provided with the necessary capital by his organization, but that the Institute facilities are available to all without any preference to the Almin group. In the absence of Lord Hives, who had gone abroad, the unveiling ceremony was performed by Sir Archibald Rowlands, permanent secretary of the Ministry of Supply, who was a close personal friend of Colonel Devereux. In a memorable and moving speech Sir Archibald described Colonel Devereux as a happy man with great abilities, enormous drive and a warm heart, who had provided in the Fulmer Research Institute something for Great Britain similar to the wellknown Battelle and Mellon Institutes of the United States.

After luncheon Lord Waverley (better known to many as Sir John Anderson) spoke on the successful efforts that have been made in Great Britain since the First World War to make good the deficiencies in the national scientific equipment, particularly in the application of science to industry. He recalled that some seven years ago at a conference of the Federation of British Industries on the application of science to industry, he had expressed regret at the absence in Britain of any institution comparable with the Rattelle and Mellon Institutes. Despite the amazing increase in scientific effort through the larger industrial units, the universities and the research associations, and other establishments under the ægis of the Department of Scientific and Industrial Research, Lord Waverley still thought there is scope for further effort and expressed the hope that the work of the Fulmer Research Institute would be multiplied many times in other fields.

After paying a personal tribute to Colonel Devereux, Mr. E. A. G. Liddiard, director of research in the Institute, outlined the progress made by the Institute over the first five years, during which the income, now approximately $£ 78,000$ a year, has more than trebled and the staff more than doubled. All the income came directly from research contracts, and the Institute received no other income in the form of endowments or government grants. About half the total income was derived from government contracts, and there was a substantial proportion of direct dollar-earning sponsorship from the United States and Canada. There was, however, a steady increase in the volume of work for British industry and he looked for further growth in the future. He considered that the problem most appropriate to a sponsored research institute is one in which research results need considerable expenditure in subsequent development work, and it is essential that those incurring these costs should be assured of a return for their expenditure and for the risk taken by having some form of monopoly in these new developments-preferably in the form of patents covering the original research results. The connexions established in the United States and Canada would, he said, help in the full exploitation of research results obtained for British sponsors.

Sir Frederick Handley Page, on behalf of the guests, thanked the hosts and stressed the opportunities available in the Institute for British industry, particularly for small firms which cannot afford the equipment or staff necessary for the solution of a particular problem.

The laboratories of the Institute were open for inspection and contained exhibits of various items of work completed and in progress. In the Physical Chemistry Section the work of Dr. P. Gross and his colleagues on the refining of metals by reactions involving metal halide vapours was illustrated. This included the determination of heats of formation of metallic halides and the equilibrium and kinetics of various reactions, particularly the reaction $2 \mathrm{Al}+\mathrm{AlCl}_{3} \rightleftharpoons 3 \mathrm{AlCl}$, which forms the basis of the so-called 'catalytic' distillation of aluminium. A small pilot-plant operating this refining process was an important feature. Samples of titanium metal produced in the laboratory by different reactions, details of which were not available, were on show together with samples of titanium trifluoride and of beryllium produced by indirect distillation.

In the Physics, Metallurgy and Engineering Sections, under Dr. A. H. Sully, alloy research included an investigation into the mechanism of age-hardening and work on aluminium-bronze and aluminium-tin bearing metals. The aluminium-copper-cadmium alloys developed by the Institute were claimed to have properties similar to the duralumin-type alloys but to be free from any tendency to age at room temperature and to have exceptionally good hot-working properties. Work on high-temperature materials included an investigation into the ductile-brittle transition of chromium and of metal-ceramic aggregates, and a good deal of interest was shown in the development of low-emissivity protective ceramic coatings for combustion chambers of gas-turbine engines. The Physics Section employs Guinier-type single and double monochromators for studying structural changes in age-hardening alloys; and in the Engineering Section high-temperature fatigue 